\title{
Attention-Deficit/Hyperactivity Disorder (ADHD) and Obesity: Update 2016
}

\author{
Samuele Cortese $^{1,2} \cdot$ Luca Tessari $^{1,3}$ \\ Published online: 19 January 2017 \\ (C) The Author(s) 2017. This article is published with open access at Springerlink.com
}

\begin{abstract}
While psychiatric comorbidities of attentiondeficit/hyperactivity disorder (ADHD) have been extensively explored, less attention has been paid to somatic conditions possibly associated with this disorder. However, mounting evidence in the last decade pointed to a possible significant association between ADHD and certain somatic conditions, including obesity. This papers provides an update of a previous systematic review on the relationship between obesity and ADHD (Cortese and Vincenzi, Curr Top Behav Neurosci 9:199-218, 2012), focusing on pertinent peer-reviewed empirical papers published since 2012. We conducted a systematic search in PubMed, Ovid, and Web of Knowledge databases (search dates: from January 1st, 2012, to July 16th, 2016). We retained a total of 41 studies, providing information on the prevalence of obesity in individuals with ADHD, focusing on the rates of ADHD in individuals with obesity, or reporting data useful to gain insight into possible mechanisms underlying the putative association between ADHD and obesity. Overall, over the past 4 years, an increasing number of studies have assessed the prevalence of obesity in individuals with ADHD or the rates of
\end{abstract}

This article is part of the Topical Collection on Attention-Deficit Disorder

Samuele Cortese

samuele.cortese@gmail.com

1 Academic Unit of Psychology, Developmental Brain-Behaviour Laboratory, University of Southampton, Southampton, UK

2 The Child Study Center at NYU Langone Medical Center, New York, NY, USA

3 Department of Woman and Child Health, University of Padua, Padua, Italy
ADHD in patients with obesity. Although findings are mixed across individual studies, meta-analytic evidence shows a significant association between ADHD and obesity, regardless of possible confounding factors such as psychiatric comorbidities. An increasing number of studies have also addressed possible mechanisms underlying the link between ADHD and obesity, highlighting the role, among others, of abnormal eating patterns, sedentary lifestyle, and possible common genetic alterations. Importantly, recent longitudinal studies support a causal role of ADHD in contributing to weight gain. The next generation of studies in the field should explore if and to which extent the treatment of comorbid ADHD in individuals with obesity may lead to long-term weight loss, ultimately improving their overall well-being and quality of life.

Keywords ADHD · Obesity · Overweight · Eating

\section{Introduction}

Attention-deficit/hyperactivity disorder (ADHD) is a major public health issue. It is one of the most frequent childhood-onset psychiatric conditions, with an estimated prevalence exceeding 5\% in school-age children [1]. It has been reported that impairing symptoms of ADHD persist into adulthood in up to $65 \%$ of childhood-onset cases [2], with a prevalence of ADHD in adults estimated at $2.5 \%$ [3]. Due to its core symptoms and associated disorders/conditions, ADHD imposes an enormous burden on society in terms of psychological dysfunction, adverse vocational outcomes, stress on families, and societal financial costs. The US annual incremental costs of ADHD have been recently estimated at \$143-\$266 billion 
[4], and costs are substantial also in other countries as well (e.g., [5]).

Whereas the comorbidity between ADHD and psychiatric disorders has been extensively explored [6], the association with somatic conditions has received much less attention. However, a mounting body of evidence on the association between neuropsychiatric disorders and medical conditions has emerged in the past years. In particular, there has been a focus on the relationship between ADHD and obesity. Gaining insight into this possible link is highly relevant from a public health perspective, given the epidemic of obesity and the substantial morbidity (including risk for cardiovascular disease, diabetes, and cancer) and increased risk of mortality associated with this condition [7].

Cortese et al. [8••] first systematically reviewed the literature on the relationship between ADHD and obesity in 2008 and updated this initial review in 2012 [9]. Given that the body of research has continuously grown since then, a further update is warranted. In this paper, we review and critically discuss papers on the relationship between ADHD and obesity/overweight published in the last 4 years (2012-2014).

\section{Methods}

Although the present paper is not intended to be a systematic review with a formal and quantitative appraisal of the quality of the studies, we performed a systematic search for original peer-reviewed papers in a set of electronic databases, including PubMed, Ovid databases (Medline, PsycINFO, Embase + Embase classic), and ISI Web of Knowledge (Web of Science [Science Citation Index Expanded], Biological Abstracts, Biosis, Food Science and Technology Abstracts). The search terms and syntax for the search in PubMed were (ADHD OR Attention-Deficit/Hyperactivity Disorder OR Attention Deficit Hyperactivity Disorder OR Hyperkinetic Syndrome) AND (obes* OR overweight). The search terms and syntax were adapted for each of the other electronic databases. References from each paper were examined to find additional studies possibly missed in the electronic search.

We searched for studies reporting information on (1) the prevalence of obesity in individuals with ADHD, (2) the prevalence of ADHD in individuals with obesity, (3) possible mechanisms underlying the putative association between ADHD and obesity, and (4) the implications of the possible association between ADHD and obesity for the clinical management of individuals with both conditions. Regarding criteria no. 1 and no. 2, we included only studies that used either a formal diagnosis of ADHD or in which the diagnosis of ADHD was self-reported. In order to avoid possible bias in the estimation of the prevalence of ADHD in individuals with obesity or of obesity in individuals with ADHD, we did not include studies in which participants presented only with ADHD symptoms above a cutoff on any scale for ADHD. However, we did not apply this exclusionary criterion when considering studies on the possible mechanisms linking ADHD and obesity, since a dimensional approach can still be informative in this respect. We did not apply any language restriction. We searched for reports published from January 1st, 2012, to July 16th, 2016.

\section{Results}

The search retrieved 3412 potentially pertinent hits. After excluding references not meeting our criteria, we retained a total of 41 [10-50] studies (Fig. 1 and Tables 1, 2, and $3)$. Table 4 reports the references excluded [51-57], with reasons for exclusion. Of the included references, 17 [10-26] provided information on the prevalence of obesity in individuals with ADHD, $2[27,28]$ included data on the prevalence of ADHD in individuals with obesity, and 28 [12, 19-22, 25, 29-46, 48-50, 58] reported data useful to gain insight into possible mechanisms underlying the putative association between ADHD and obesity (We note that references providing information both on the prevalence of obesity in individuals with ADHD and obesity and on possible mechanisms were counted twice). Of note, none of the retrieved studies addressed the implications of the association between ADHD and obesity for the management of patients with both conditions.

Details of the studies retained in our review are presented in Tables 1, 2, and 3, which show first study author, year of publication, country (or countries) where the study was carried out, and study key findings. The results of these studies are reported in the following sections, highlighting how studies published after 2012 advance previous knowledge summarized in Cortese and Vincenzi [9].

\section{Prevalence of Obesity/Overweight in Individuals With ADHD}

Cortese and Vincenzi [9] reviewed 12 studies [59-70]. Of these, six $[61,63-65,69]$ more specifically compared the rates of obesity/overweight between individuals with ADHD and without ADHD (or from the general population). Overall, Cortese and Vincenzi [9] concluded that studies in both clinical and epidemiological samples suggested that individuals with ADHD have higher than average BMI-SDS or a higher prevalence of obesity 
Fig. 1 Preferred Reporting Items for Systematic Reviews and Meta-Analyses (PRISMA) flowchart

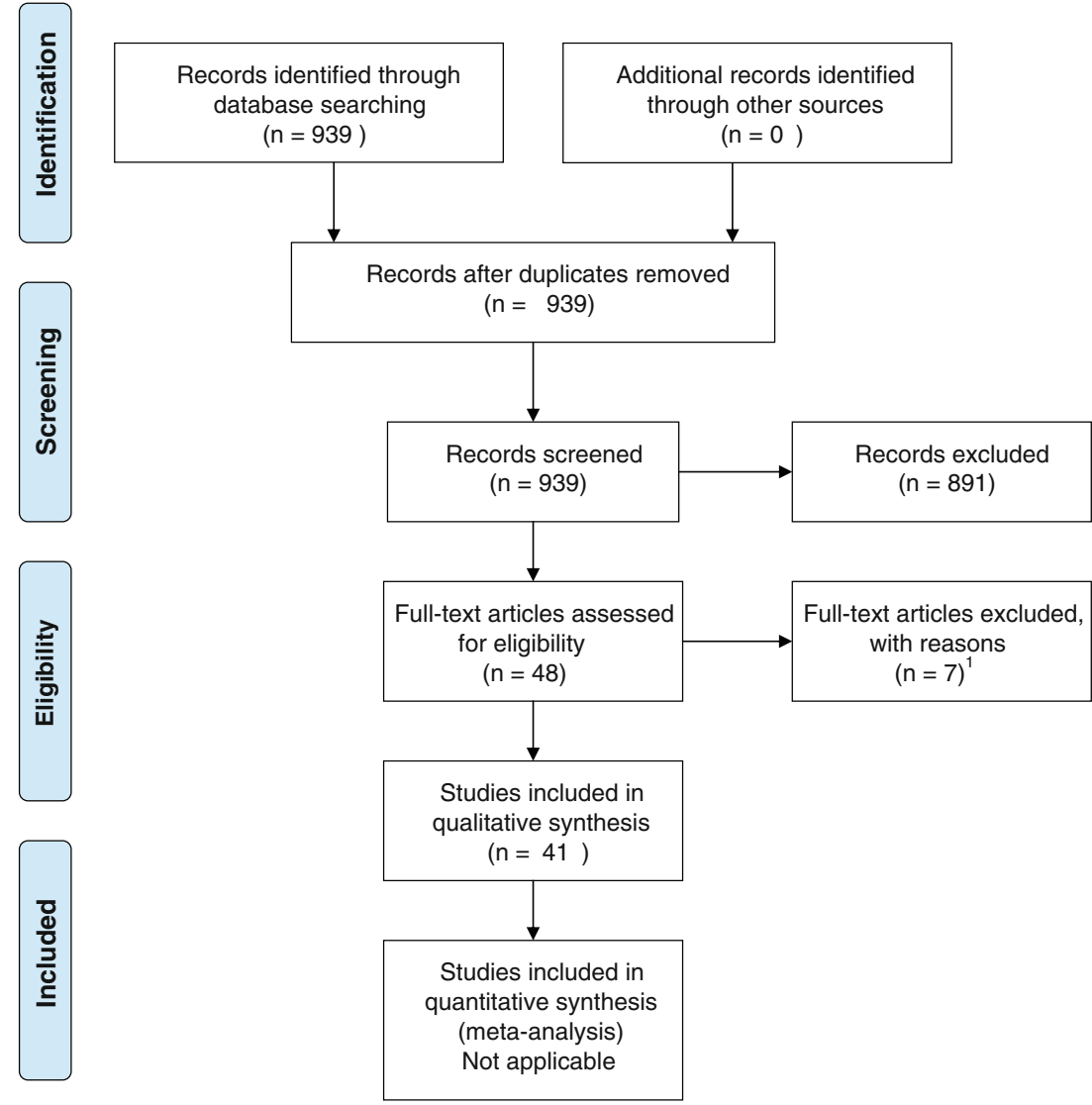

compared to non-ADHD subjects. However, one of the drawbacks highlighted by Cortese and Vincenzi [9] was that a sizable portion of studies had not controlled for the possible confounding effect of psychiatric comorbidities, so that it was not possible to establish to which extent the increased rates of obesity/overweight found in individuals with ADHD are accounted for by ADHD per se or by comorbid psychiatric disorders. In our updated search focused on the last 4 years, we found 17 additional studies reporting rates of obesity/overweight in individuals with ADHD. As shown in Table 1, overall findings from these studies are still mixed. While some studies showed significantly higher rates of obesity in individuals with compared to those without ADHD, even after controlling for possible confounding factors, others did not. Additionally, the impact of psychostimulant treatment was not consistent across studies, with some of them showing a significant reduction of the rates of obesity in individuals treated with psychostimulants and others not confirming such finding. However, importantly, given the increasing number of studies, recently, this body of search has been recently meta-analyzed. In fact, currently two meta-analyses have been published by two different groups. In the first meta-analysis, Cortese et al. [71••] pooled 42 studies, including a total of 48,161 ADHD subjects and 679,975 comparison subjects. Cortese et al. [71••] found that a significant association between obesity and ADHD was found for both children (odds ratio $=1.20,95 \%$ $\mathrm{CI}=1.05-1.37)$ and adults (odds ratio $=1.55,95 \%$ $\mathrm{CI}=1.32-1.81$ ). The pooled prevalence of obesity was increased by about $70 \%$ in adults with ADHD (28.2\%, 95\% CI $=22.8-34.4)$ compared with those without ADHD (16.4\%, 95\% CI $=13.4-19.9)$, and by about $40 \%$ in children with ADHD $(10.3 \%, 95 \% \mathrm{CI}=7.9-13.3) \mathrm{com}$ pared with those without ADHD (7.4\%, 95\% CI $=5.4$ 10.1). Interestingly, the significant association remained when limiting the analysis to studies reporting odds ratio adjusted for possible confounding factors (such as low socioeconomic status, comorbid depression, or comorbid anxiety). Gender, study setting, study country, and study quality did not moderate the association between obesity and ADHD. Additionally, ADHD was also significantly associated with overweight. Importantly, individuals medicated for ADHD were not at higher risk of obesity, suggesting that ADHD pharmacological treatment may exert a protective action on the risk of development of obesity, although the meta-analysis could not prove this assumption. In the second meta-analysis by Nigg et al. [20••], published after the one by Cortese et al. [71••], the authors confirmed a significant association between ADHD and obesity (odd ratio $=1.22(95 \% \mathrm{CI}=1.11-1.34)$, highlighting that the association was larger in adults 


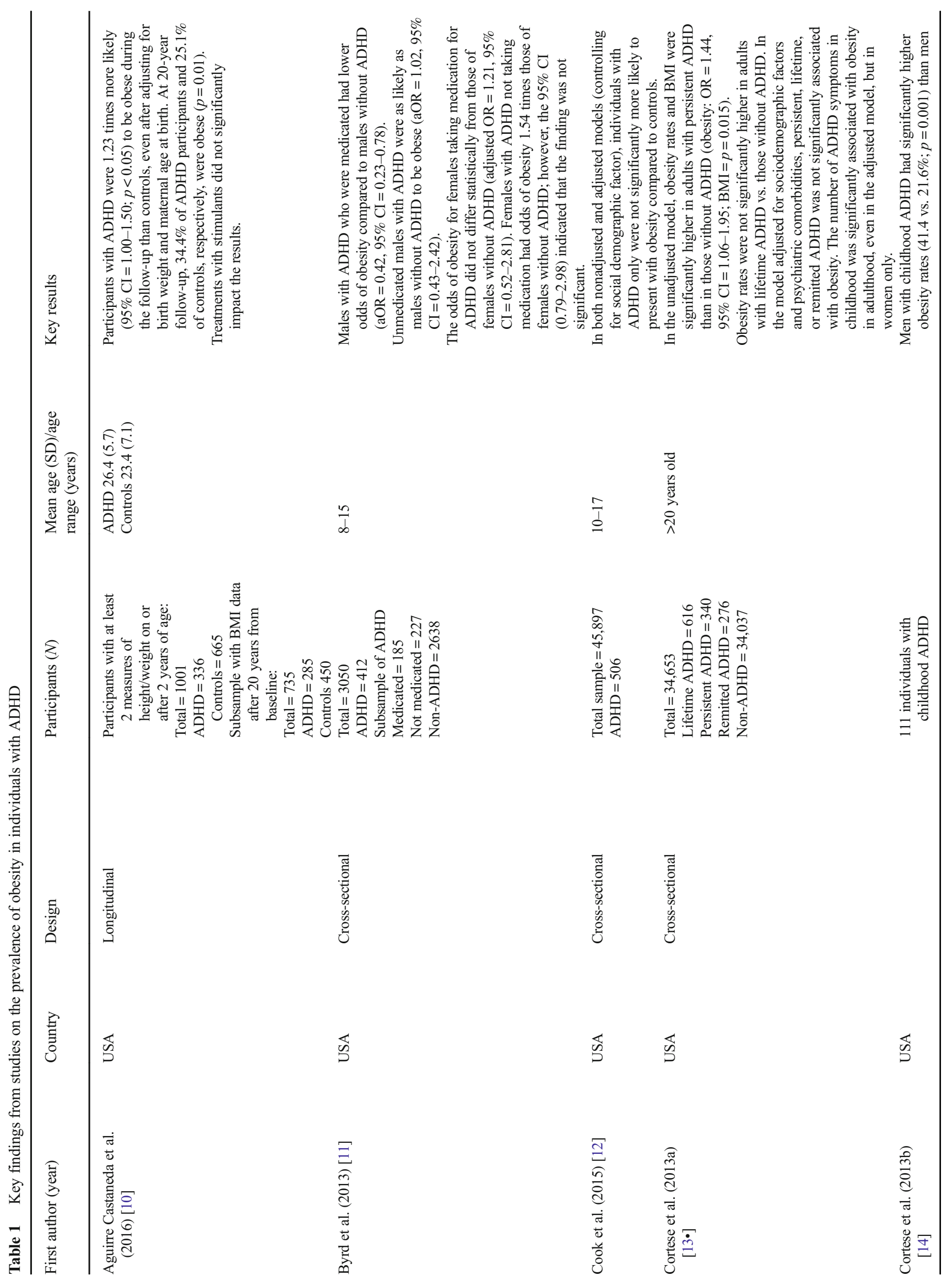




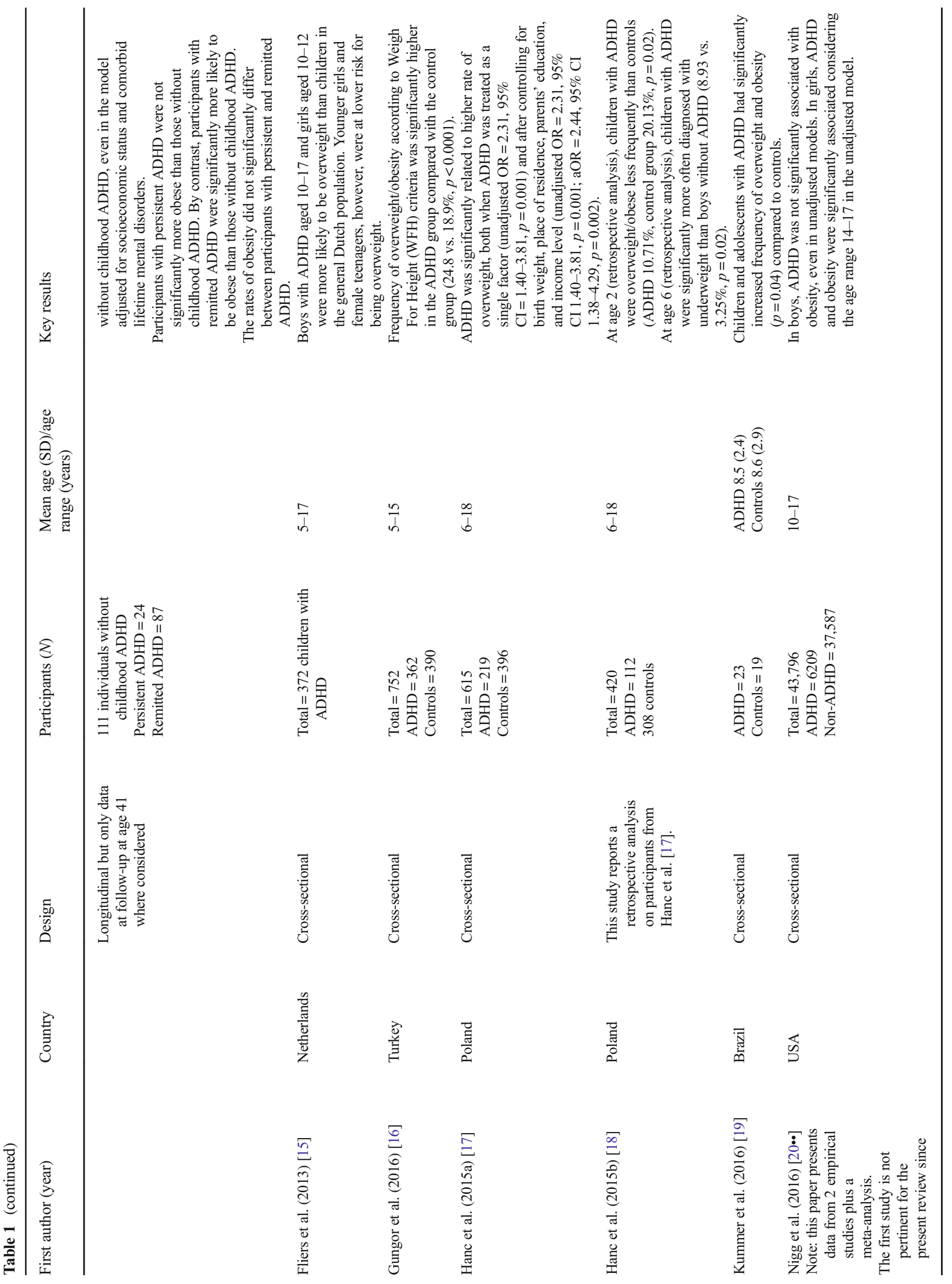




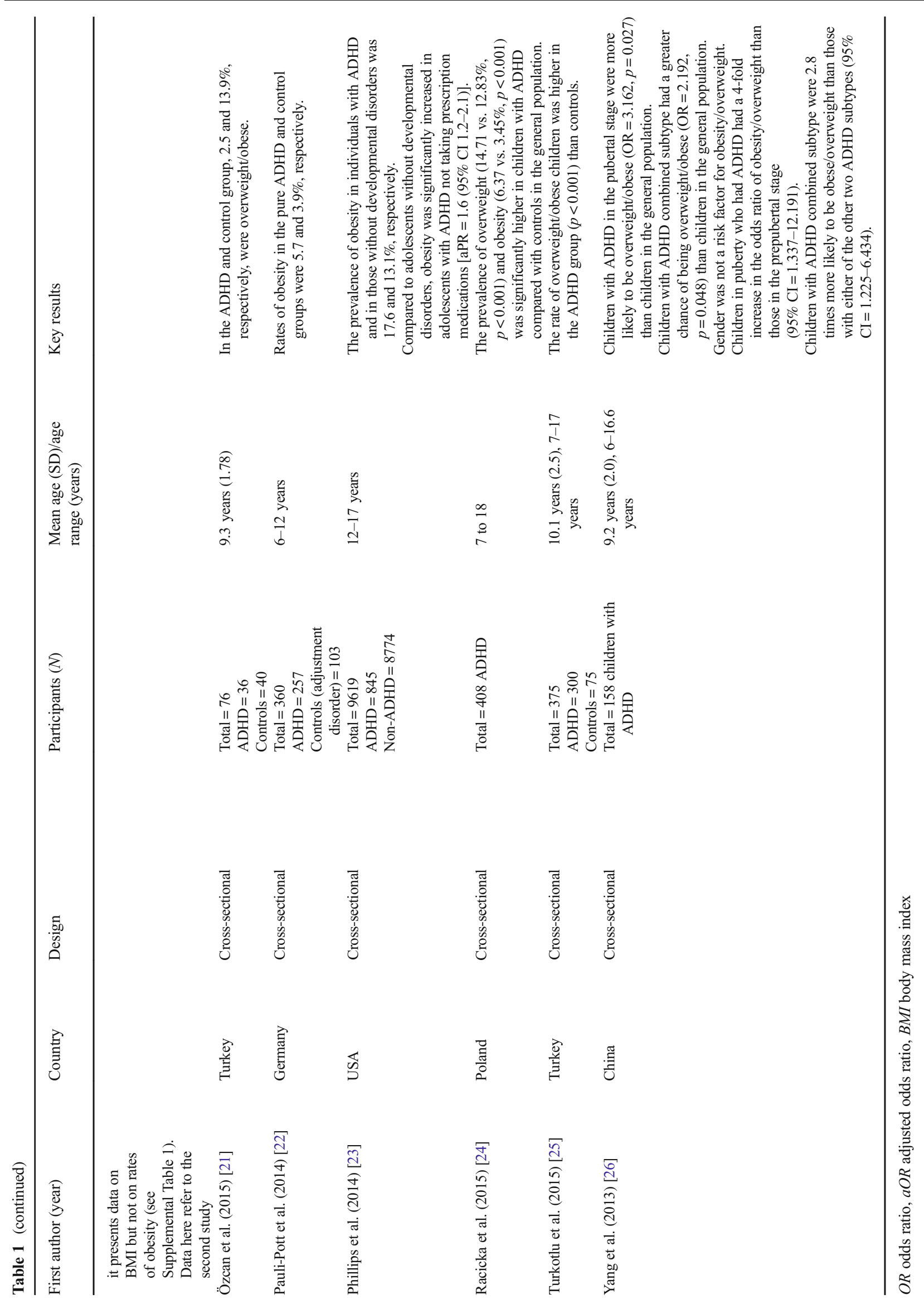


Table 2 Key findings from studies on the prevalence of ADHD in individuals with obesity

\begin{tabular}{|c|c|c|c|c|c|}
\hline First author (year) & Country & Design & Participants $(N)$ & $\begin{array}{l}\text { Mean age }(\mathrm{SD}) / \text { age } \\
\text { range (years) }\end{array}$ & Key results \\
\hline $\begin{array}{l}\text { Halfon et al. } \\
\text { (2013) [27] }\end{array}$ & USA & Cross-sectional & $\begin{array}{l}\text { Total }=43,297 \\
43,106 \text { population with } \\
\text { available records } \\
\text { ADHD }=3879(9 \%) \\
\text { Non-ADHD }=39,418 \\
\quad(91 \%)\end{array}$ & $10-17$ & $\begin{array}{l}\text { Children with obesity not taking stimulan } \\
\text { medication were significantly more } \\
\text { likely to present with ADHD comparec } \\
\text { to nonoverweight children (OR }=1.93 \text {, } \\
\text { 95\% CI 1.26-2.94; aOR } 1.85,95 \% \\
\text { CI 1.18-2.92). This finding was not } \\
\text { significant when considering obese } \\
\text { children taking stimulant medication. }\end{array}$ \\
\hline $\begin{array}{l}\text { Perez-Bonaventura } \\
\text { et al. (2015) [28] }\end{array}$ & Spain & Longitudinal & $\begin{array}{l}\text { Participants available at } \\
\text { age of } 3 \text { years }=611 \\
\text { ADHD nonoverweight } \\
(558,3.3 \%)=20 \\
\text { ADHD overweight } \\
(53,8.3 \%)=4 \\
\text { Total ADHD }=24 \\
\text { Participants available } \\
\text { at age of } 4 \text { years }=596 \\
\text { ADHD nonoverweight } \\
(541,4.4 \%)=24 \\
\text { ADHD overweight } \\
(55,13.6 \%)=7 \\
\text { Total ADHD }=31\end{array}$ & $\begin{array}{l}\text { All patients tested } \\
\text { at } 3,4 \text {, and } 5 \\
\text { years }\end{array}$ & $\begin{array}{l}\text { At age } 4 \text { years, being overweight was } \\
\text { associated with higher percentages of } \\
\text { ADHD. A higher BMI } z \text {-score at age } \\
3 \text { years was related to higher mean } \\
\text { scores in hyperactivity problems, peer } \\
\text { relationship problems, and total } \\
\text { difficulties and to higher percentages } \\
\text { for ADHD at age } 4 \text { years. }\end{array}$ \\
\hline
\end{tabular}

$O R$ odds ratio, $a O R$ adjusted odds ratio, $B M I$ body mass index

(odd ratio $=1.37[1.19-1.58])$ than in youth (odd ratio $=1.13[1.00-1.27])$.

\section{Prevalence of ADHD in Individuals With Obesity/Overweight}

Cortese and Vincenzi [9] presented a total of five studies [72-76] exploring the prevalence of ADHD in individuals referred for specialist treatment of obesity. All these studies, with the exception of Braet et al. [74], reported significantly higher rates of ADHD in individuals with obesity compared to controls (either nonobese or general population). In our update, we located an additional two studies [27, 28] both confirming significantly higher rates of ADHD (as categorical diagnosis) in individuals with obesity compared to normal weight controls (Table 2). Of note, the meta-analysis by Cortese et al. [71••] excluded studies of individuals in bariatric clinics because these individuals represent a subsample of severely obese individuals, whereas their meta-analysis focused on the association between ADHD and any degree of obesity.

Taking together the two types of studies (focusing on rates of obesity in individuals with ADHD and on the prevalence ADHD in individuals with obesity, respectively), it is fair to state that evidence supports a bidirectional relationship between ADHD and obesity, irrespective of possible confounding factors.

\section{Studies Suggesting Possible Mechanisms Underlying the Association Between ADHD and Obesity}

When Cortese and Vincenzi [9] wrote their review in 2012, there was a paucity of studies addressing the possible mechanisms underlying the association between ADHD and obesity/overweight. Since all the studies that they reviewed on the link between the two conditions were cross-sectional, Cortese and Vincenzi [9] hypothesized three pathways: (1) obesity/overweigh or factors associated with obesity/overweight (such as sleep-disordered breathing) lead to ADHD symptoms, (2) ADHD and obesity are underpinned common biological dysfunction, and (3) ADHD contributes to obesity. Overall, beyond case reports, they only found initial evidence from empirical studies pointing to a role of abnormal eating patterns (including binge eating) mediating a link between ADHD and overweight, possibly supporting hypothesis no. 3 but not excluding hypothesis no. 1 [77-79].

Over the past 4 years, there have been remarkable progresses in the understanding of the possible mechanisms linking ADHD and obesity. In fact, we located 28 studies [12, 19-22, 25, 29-46, 48-50, 58] (Table 3). Several of these studies $[32,36,42-44,46]$ provide support to the notion that abnormal eating patterns may contribute to the increased risk of obesity in individuals with ADHD, although the crosssectional nature of the majority of the studies cannot prove causality. Another series of studies has also pointed to a 


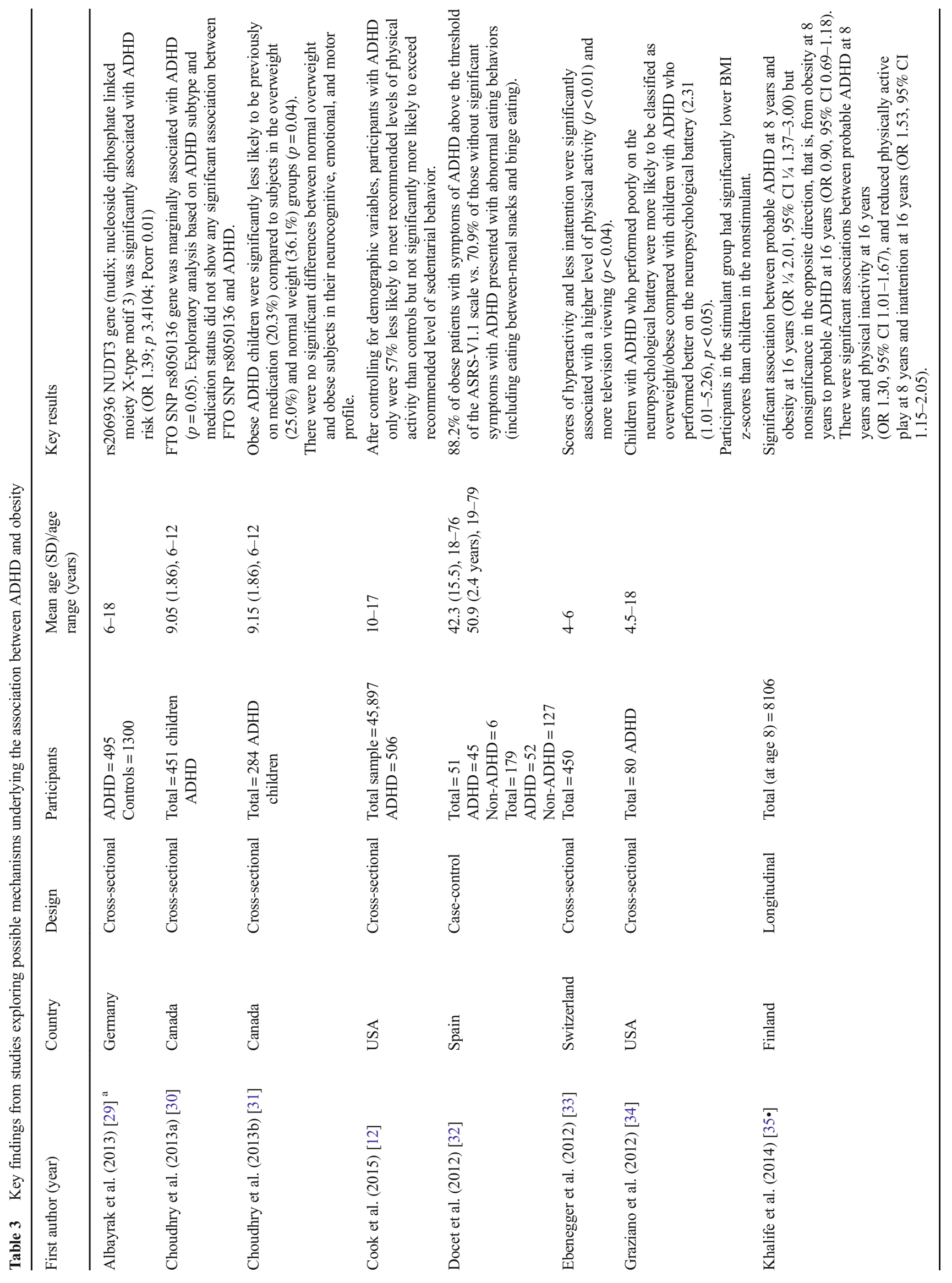




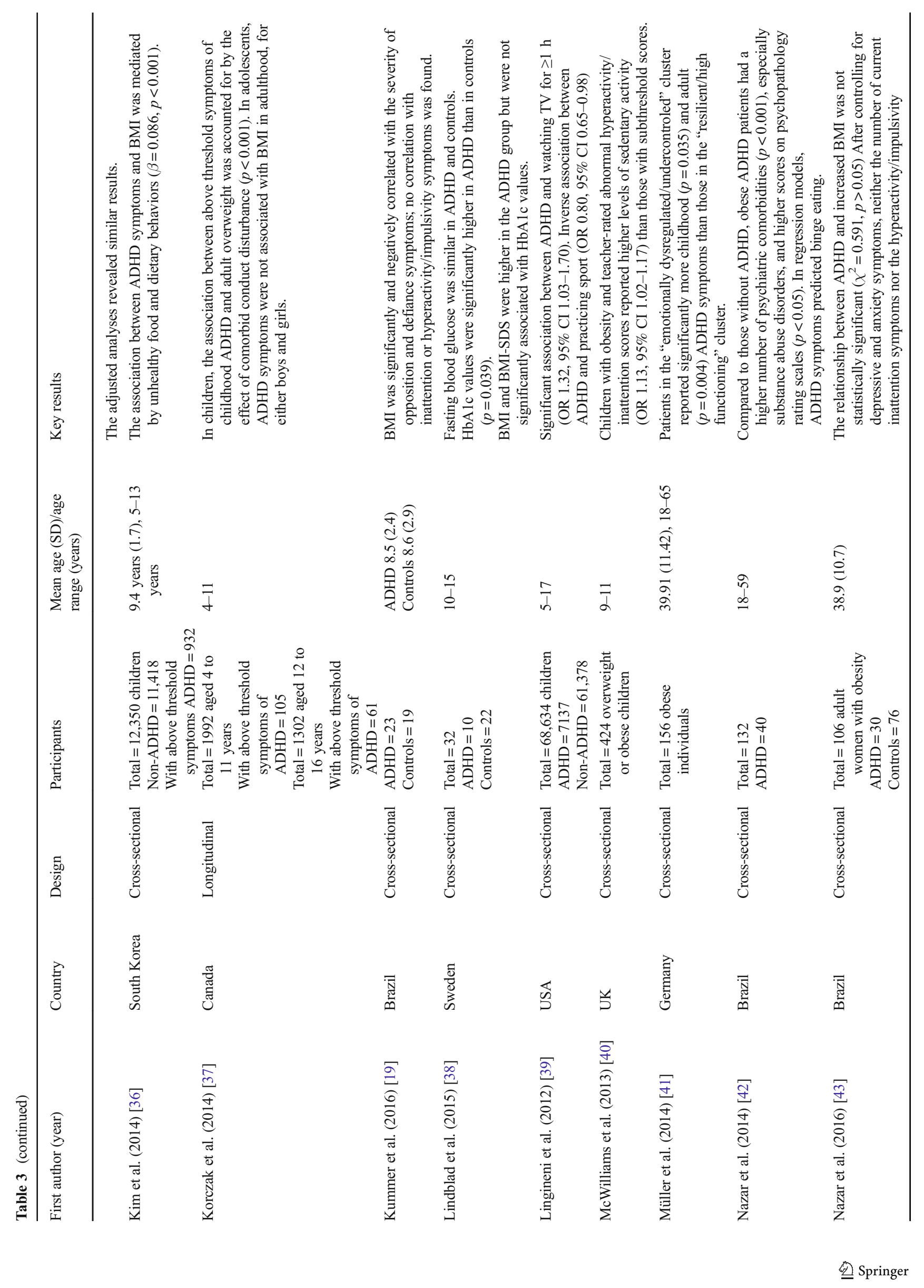




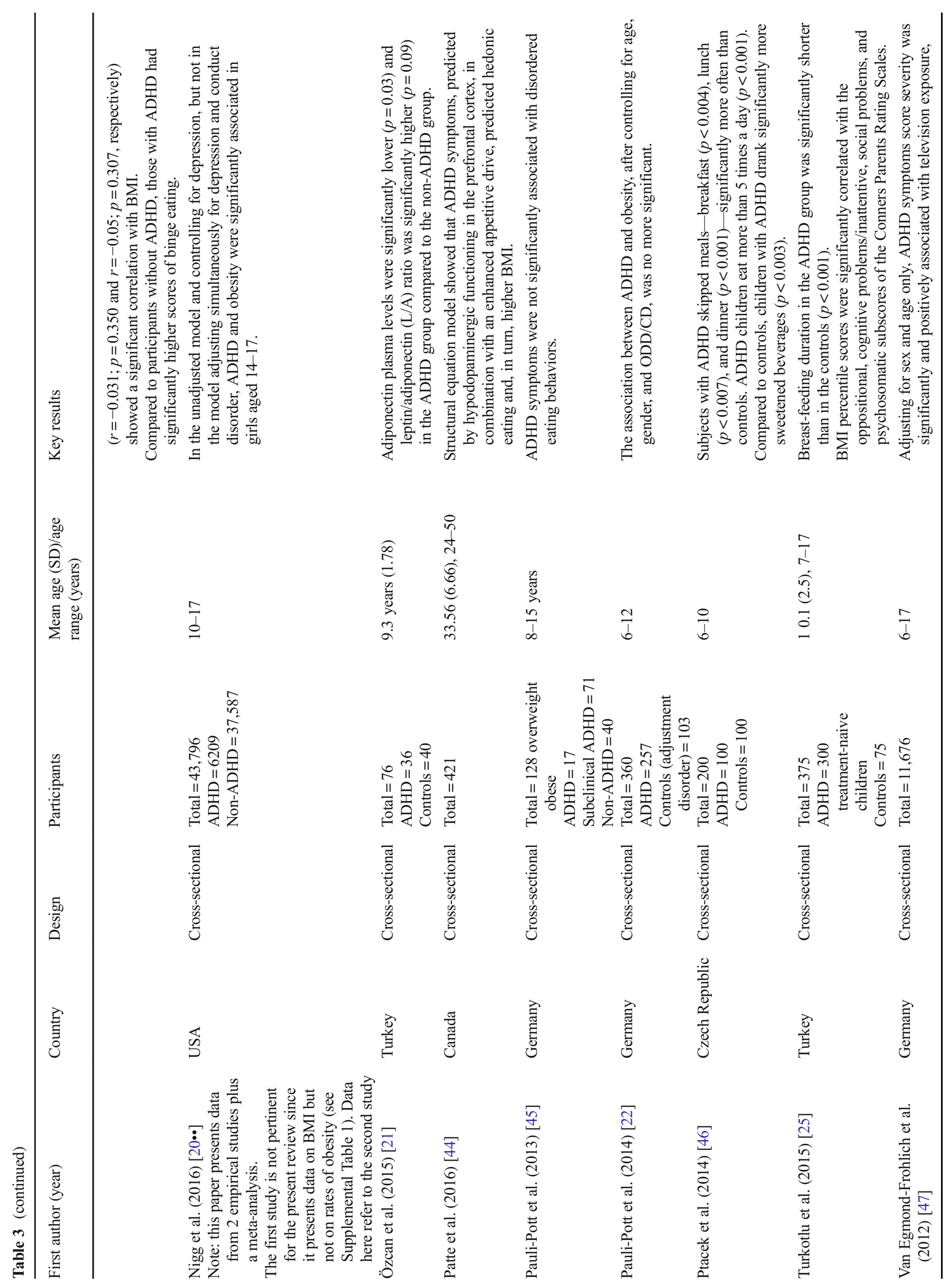




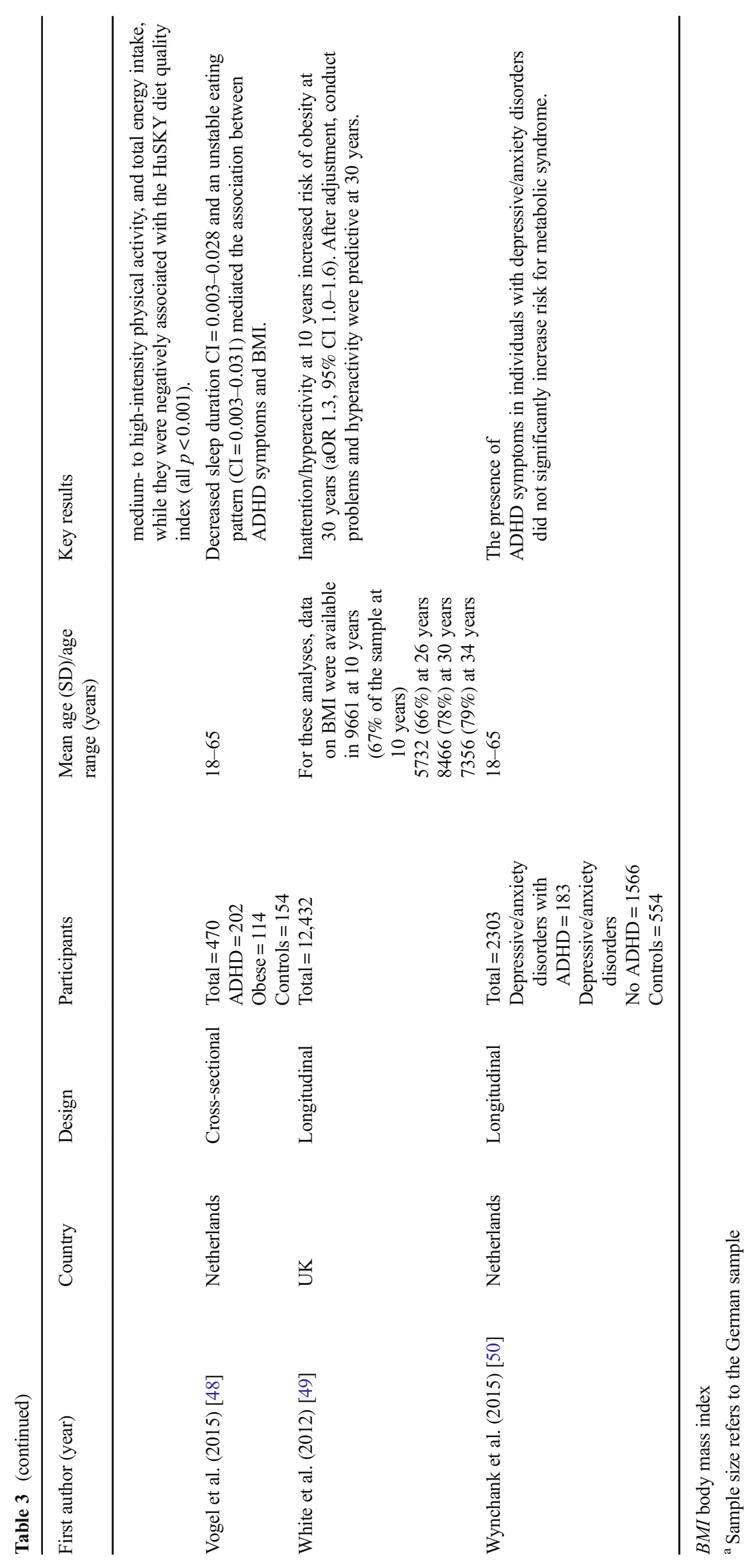


Table 4 Studies excluded, with reasons for exclusion

\begin{tabular}{ll}
\hline First author (year) & Reason for exclusion \\
\hline Erhart et al. (2012) [51] & No formal ADHD diagnosis \\
Goulardins et al. (2016) [52] & No formal ADHD diagnosis \\
Hanc et al. (2012) [53] & No data on overweight/obesity \\
Ja (2014) [54] & No formal ADHD diagnosis \\
Kerekes et al. (2015) [55] & No formal ADHD diagnosis \\
McClure et al. (2012) [56] & No formal ADHD diagnosis \\
Nigg et al. (2016) [20•• ${ }^{\mathrm{a}}$ & The first study of this paper is not \\
& pertinent to the present review \\
& since it presents data on BMI \\
& but not on rates of obesity \\
Pagoto et al. (2012) [57] & Review (treatment) without empirical \\
& data
\end{tabular}

${ }^{a}$ This reference is not counted in the PRISMA flowchart in Fig. 1 since the second empirical study reported in it provides data on the prevalence of obesity in individuals with ADHD

possible role of decreased physical activity (less involvement in sport activities) or increased hours/day spent watching TV, in individuals with ADHD compared to controls, as a possible mechanism favoring abnormal weigh gain associated with ADHD $[12,33,35 \cdot, 39,40,58]$. Additionally, there have been also some studies suggesting that comorbid conduct disorder, in addition to or rather than ADHD core symptoms, might contribute to the link between obesity and ADHD [19, 22, $25,37,49,50]$. This initial insight should be further developed in future research. Moreover, researchers started addressing possible common neurobiological underpinnings of obesity and ADHD. Two studies [29, 30] among the ones that we retrieved focused on the genetic mechanisms: the first one [29] suggested a possible role of rs206936 NUDT3 gene (nudix; nucleoside diphosphate linked moiety X-type motif 3 ); the second one [30] found a marginally significant association with the FTO SNP rs8050136 gene. Finally, the hypothesis by Cortese and Vincenzi [9] that sleep disruption could be involved in the association between ADHD and obesity has been initially tested and supported [48].

Importantly, in the last 4 years, longitudinal studies have explored the direction of the link between ADHD and obesity. Three studies retrieved in our search showed that ADHD chronologically precedes, and likely contributes to, weigh gain $[10,35 \cdot 49]$. However, another study has shown the reverse pattern [28]. It is indeed possible that bidirectional pathways are involved.

\section{Studies on the Clinical Implications of the Association Between ADHD and Obesity}

Cortese and Vincenzi [9] cited the study by Levy et al. [80] which provided preliminary evidence showing that the screening and pharmacological treatment of previously overlooked ADHD in adults with refractory obesity leads to beneficial effects on weight gain. Clearly, a possible important confounder of this study is the anorexigenic effect associated with psychostimulants. However, Levy et al. [80] noted that appetite reduction was evident in the first 4-6 weeks of treatment, but then it diminished and vanished in most subjects within 2 months. Therefore, the authors of the study concluded that it is unlikely that the anorexigenic effect of psychostimulants contributed to weight loss at followup, after more than 1 year from the start of treatment. Rather, they highlighted how the pharmacological treatment of ADHD led to "self-directedness, a reduction in novelty seeking, and an increased capacity for persistence," which in turn enhanced adherence to diet and ultimately led to weight loss. However, given the naturalistic design of this study, its conclusions should be considered as preliminary and further replication using more rigorous designs is warranted.

Unfortunately, since then, no other studies have been published directly testing, by means of a randomized design, the effects of ADHD screening and treatment of obesity outcomes. However, evidence from recent studies, including those retrieved in our search (e.g., [31] and [34]), supports the notion that individuals with ADHD pharmacologically treated are not at increased risk of obesity.

\section{Conclusions}

Over the past 4 years, there has been an increasing interest for the relationship between ADHD and obesity. Studies that addressed the questions: "Is obesity (or overweight) more frequent in individuals with, compared to those without, ADHD?" or "Is there a significant relationship between ADHD and obesity/overweight?" provide overall mixed findings, likely due to heterogeneity in diagnostic methods for ADHD and obesity, population characteristics (e.g., comorbidities), and medication status. However, meta-analytical evidence controlling for these confounding factors support a significant association between nontreated ADHD and obesity.

Remarkably, in the past 4 years, a large number of studies have contributed to our insight on the factors underlying the links between ADHD and obesity. Such body of research has pointed to the role of abnormal (dysregulated) eating patterns, decreased physical activity, sleep disruption, and psychiatric comorbidities, including conduct disorder. Preliminary evidence has also revealed possible common genetic underpinnings. Importantly, longitudinal studies have been published that show how ADHD may be a risk for the future 
development of obesity, although the reverse causal link cannot be ruled out.

Given the epidemic of obesity, if ADHD does contribute to it, understanding how and to which extent the treatment of comorbid ADHD in individuals with obesity may lead to long-term weight loss in individuals with obesity, improving adherence to diet programs is fundamental. There is a paucity of studies on this issue and we believe that this should receive further attention in future research. This line of research has ultimately the potential to improve the clinical management and, as a consequence, the quality of individuals with both ADHD and obesity.

\section{Compliance with Ethical Standards}

Conflict of Interest Samuele Cortese and Luca Tessari declare that they have no conflict of interest.

Human and Animal Rights and Informed Consent This article does not contain any studies with human or animal subjects performed by any of the authors.

Open Access This article is distributed under the terms of the Creative Commons Attribution 4.0 International License (http:// creativecommons.org/licenses/by/4.0/), which permits unrestricted use, distribution, and reproduction in any medium, provided you give appropriate credit to the original author(s) and the source, provide a link to the Creative Commons license, and indicate if changes were made.

\section{References}

Papers of particular interest, published recently, have been highlighted as:

- Of importance

•• Of major importance

1. Polanczyk G, de Lima MS, Horta BL, Biederman J, Rohde LA. The worldwide prevalence of ADHD: a systematic review and metaregression analysis. Am J Psychiatry. 2007;164:942-8.

2. Faraone SV, Biederman J, Mick E. The age-dependent decline of attention deficit hyperactivity disorder: a meta-analysis of followup studies. Psychol Med. 2006;36:159-65.

3. Simon V, Czobor P, Balint S, Meszaros A, Bitter I. Prevalence and correlates of adult attention-deficit hyperactivity disorder: metaanalysis. Br J Psychiatry. 2009;194:204-11.

4. Doshi JA, Hodgkins P, Kahle J, Sikirica V, Cangelosi MJ, Setyawan $\mathrm{J}$, et al. Economic impact of childhood and adult attention-deficit/ hyperactivity disorder in the United States. J Am Acad Child Adolesc Psychiatry. 2012;51:990-1002 e1002.

5. Hakkaart-van Roijen L, Zwirs BW, Bouwmans C, Tan SS, Schulpen TW, Vlasveld L, et al. Societal costs and quality of life of children suffering from attention deficient hyperactivity disorder (ADHD). Eur Child Adolesc Psychiatry. 2007;16:316-26.

6. Biederman J, Faraone SV. Attention-deficit hyperactivity disorder. Lancet. 2005;366:237-48.

7. Ng M, Fleming T, Robinson M, Thomson B, Graetz N, Margono C, et al. Global, regional, and national prevalence of overweight and obesity in children and adults during 1980-2013: a systematic analysis for the global burden of disease study 2013. Lancet. 2014;384: 766-81.

8.• Cortese S, Angriman M, Maffeis C, Isnard P, Konofal E, Lecendreux $\mathrm{M}$, et al. Attention-deficit/hyperactivity disorder (ADHD) and obesity: a systematic review of the literature. Crit Rev Food Sci Nutr. 2008;48:524-37. The first systematic review on ADHD and obesity.

9. Cortese S, Vincenzi B. Obesity and ADHD: clinical and neurobiological implications. Curr Top Behav Neurosci. 2012;9:199-218.

10. Aguirre Castaneda RL, Kumar S, Voigt RG, Leibson CL, Barbaresi WJ, Weaver AL, et al. Childhood attention-deficit/hyperactivity disorder, sex, and obesity: a longitudinal population-based study. Mayo Clin Proc. 2016;91:352-61.

11. Byrd HCM, Curtin C, Anderson SE. Attention-deficit/hyperactivity disorder and obesity in US males and females, age $8-15$ years: National Health and Nutrition Examination Survey 2001-2004. Pediatr Obes. 2013;8:445-53.

12. Cook BG, Li D, Heinrich KM. Obesity, physical activity, and sedentary behavior of youth with learning disabilities and ADHD. J Learn Disabil. 2015;48:563-76.

13. Cortese S, Faraone SV, Bernardi S, Wang S, Blanco C. Adult attention-deficit hyperactivity disorder and obesity: epidemiological study. Br J Psychiatry. 2013;203:24-34. One of the largest population-based studies on ADHD and obesity.

14. Cortese S, Ramos Olazagasti MA, Klein RG, Castellanos FX, Proal E, Mannuzza S. Obesity in men with childhood ADHD: a 33-year controlled, prospective, follow-up study. Pediatrics. 2013;131: e1731-1738.

15. Fliers EA, Buitelaar JK, Maras A, Bul K, Hohle E, Faraone SV, et al. ADHD is a risk factor for overweight and obesity in children. J Dev Behav Pediatr. 2013;34:566-74.

16. Gungor S, Celiloglu OS, Raif SG, Ozcan OO, Selimoglu MA. Malnutrition and obesity in children with ADHD. J Atten Disord. 2016;20:647-52.

17. Hanc T, Slopien A, Wolanczyk T, Dmitrzak-Weglarz M, Szwed A, Czapla Z, et al. ADHD and overweight in boys: cross-sectional study with birth weight as a controlled factor. Eur Child Adolesc Psychiatry. 2015;24:41-53.

18. Hanc T, Slopien A, Wolanczyk T, Szwed A, Czapla Z, Durda M, et al. Attention-deficit/hyperactivity disorder is related to decreased weight in the preschool period and to increased rate of overweight in school-age boys. J Child Adolesc Psychopharmacol. 2015;25: 691-700.

19. Kummer A, Barbosa IG, Rodrigues DH, Rocha NP, Rafael MDS, Pfeilsticker L, et al. Frequency of overweight and obesity in children and adolescents with autism and attention deficit/hyperactivity disorder. Revista Paulista de Pediatria: Orgao Oficial da Sociedade de Pediatria de Sao Paulo. 2016;34:71-7.

20.• Nigg JT, Johnstone JM, Musser ED, Long HG, Willoughby MT, Shannon J. Attention-deficit/hyperactivity disorder (ADHD) and being overweight/obesity: new data and meta-analysis. Clin Psychol Rev. 2016;43:67-79. The most recent meta-analysis on ADHD and obesity.

21. Ozcan O, Arslan M, Gungor S, Yuksel T, Selimoglu MA. Plasma leptin, adiponectin, neuropeptide $\mathrm{Y}$ levels in drug naive children with ADHD. J Atten Disord. 2015.

22. Pauli-Pott U, Neidhard J, Heinzel-Gutenbrunner M, Becker K. On the link between attention deficit/hyperactivity disorder and obesity: do comorbid oppositional defiant and conduct disorder matter? Eur Child Adolesc Psychiatry. 2014;23:531-7.

23. Phillips KL, Schieve LA, Visser S, Boulet S, Sharma AJ, Kogan $\mathrm{MD}$, et al. Prevalence and impact of unhealthy weight in a national sample of US adolescents with autism and other learning and behavioral disabilities. Matern Child Health J. 2014;18:1964-75. 
24. Racicka E, Hanc T, Giertuga K, Brynska A, Wolanczyk T. Prevalence of overweight and obesity in children and adolescents with ADHD: the significance of comorbidities and pharmacotherapy. J Atten Disord. 2015.

25. Turkotlu S, Bilgic A, Akca OF. ADHD symptoms, breastfeeding and obesity in children and adolescents. Pediatr Int. 2015;57:546-51.

26. Yang R, Mao S, Zhang S, Li R, Zhao Z. Prevalence of obesity and overweight among Chinese children with attention deficit hyperactivity disorder: a survey in Zhejiang province, china. BMC Psychiatry. 2013;13:133.

27. Halfon N, Larson K, Slusser W. Associations between obesity and comorbid mental health, developmental, and physical health conditions in a nationally representative sample of US children aged 10 to 17. Acad Pediatr. 2013;13:6-13.

28. Perez-Bonaventura I, Granero R, Ezpeleta L. The relationship between weight status and emotional and behavioral problems in Spanish preschool children. J Pediatr Psychol. 2015;40:455-63.

29. Albayrak O, Putter C, Volckmar A-L, Cichon S, Hoffmann P, Nothen MM, et al. Common obesity risk alleles in childhood attention-deficit/hyperactivity disorder. Am J Med Genet B Neuropsychiatr Genet. 2013;162:295-305.

30. Choudhry Z, Sengupta SM, Grizenko N, Thakur GA, Fortier M-E, Schmitz N, et al. Association between obesity-related gene FTO and ADHD. Obesity. 2013;21:E738-44.

31. Choudhry Z, Sengupta SM, Grizenko N, Harvey WJ, Fortier M-E, Schmitz N, et al. Body weight and ADHD: examining the role of self-regulation. Plos One. 2013;8.

32. Docet M, Larranaga A, Perez Mendez L, Garcia-Mayor R. Attention deficit hyperactivity disorder increases the risk of having abnormal eating behaviours in obese adults. Eat Weight Disord. 2012;17:e132-6.

33. Ebenegger V, Marques-Vidal PM, Munsch S, Quartier V, Nydegger A, Barral J, et al. Relationship of hyperactivity/inattention with adiposity and lifestyle characteristics in preschool children. $\mathrm{J}$ Child Neurol. 2012;27:852-8.

34. Graziano PA, Bagner DM, Waxmonsky JG, Reid A, McNamara JP, Geffken GR. Co-occurring weight problems among children with attention deficit/hyperactivity disorder: the role of executive functioning. Int J Obes (Lond). 2012;36:567-72.

35. Khalife N, Kantomaa M, Glover V, Tammelin T, Laitinen J, Ebeling $\mathrm{H}$, et al. Childhood attention-deficit/hyperactivity disorder symptoms are risk factors for obesity and physical inactivity in adolescence. J Am Acad Child Adolesc Psychiatry. 2014;53:425-36. A longitudinal study providing insight into the causal relationship between ADHD and obesity.

36. Kim EJ, Kwon HJ, Ha M, Lim MH, Oh SY, Kim JH, et al. Relationship among attention-deficit hyperactivity disorder, dietary behaviours and obesity. Child Care Health Dev. 2014;40:698-705.

37. Korczak DJ, Lipman E, Morrison K, Duku E, Szatmari P. Child and adolescent psychopathology predicts increased adult body mass index: results from a prospective community sample. J Dev Behav Pediatr. 2014;35:108-17.

38. Lindblad F, Eickhoff M, Forslund AH, Isaksson J, Gustafsson J. Fasting blood glucose and HbAlc in children with ADHD. Psychiatry Res. 2015;226:515-6.

39. Lingineni RK, Biswas S, Ahmad N, Jackson BE, Bae S, Singh KP. Factors associated with attention deficit/hyperactivity disorder among US children: results from a national survey. BMC Pediatr. 2012;12:50.

40. McWilliams L, Sayal K, Glazebrook C. Inattention and hyperactivity in children at risk of obesity: a community cross-sectional study. BMJ Open. 2013;3

41. Muller A, Claes L, Wilderjans TF, de Zwaan M. Temperament subtypes in treatment seeking obese individuals: a latent profile analysis. Eur Eat Disord Rev. 2014;22:260-6.
42. Nazar BP, Suwwan R, de Sousa Pinna CM, Duchesne M, Freitas $\mathrm{SR}$, Sergeant J, et al. Influence of attention-deficit/hyperactivity disorder on binge eating behaviors and psychiatric comorbidity profile of obese women. Compr Psychiatry. 2014;55:572-8.

43. Nazar BP, de Sousa Pinna CM, Suwwan R, Duchesne M, Freitas $\mathrm{SR}$, Sergeant J, et al. ADHD rate in obese women with binge eating and bulimic behaviors from a weight-loss clinic. J Atten Disord. 2016;20:610-6.

44. Patte KA, Davis CA, Levitan RD, Kaplan AS, Carter-Major J, Kennedy JL. A behavioral genetic model of the mechanisms underlying the link between obesity and symptoms of ADHD. J Atten Disord. 2016.

45. Pauli-Pott U, Becker K, Albayrak O, Hebebrand J, Pott W. Links between psychopathological symptoms and disordered eating behaviors in overweight/obese youths. Int J Eat Disord. 2013;46:15663.

46. Ptacek R, Kuzelova H, Stefano GB, Raboch J, Sadkova T, Goetz M, et al. Disruptive patterns of eating behaviors and associated lifestyles in males with ADHD. Med Sci Monit. 2014;20:608-13.

47. van Egmond-Frohlich A, Widhalm K, de Zwaan M. Association of symptoms of attention-deficit/hyperactivity disorder with childhood overweight adjusted for confounding parental variables. Int J Obes. 2012;36:963-8.

48. Vogel S, Bijlenga D, Tanke M, Bron T, Van Der Heijden K, Swaab $\mathrm{H}$, et al. Circadian rhythm disruption as a link between attentiondeficit/hyperactivity disorder and obesity? J Psychosom Res. 2015;7:S71-2.

49. White B, Nicholls D, Christie D, Cole TJ, Viner RM. Childhood psychological function and obesity risk across the lifecourse: findings from the 1970 British cohort study. Int J Obes. 2012;36:511-6.

50. Wynchank D, Bijlenga D, Lamers F, Kooij S, Bron A, Beekman A, et al. The association between metabolic syndrome, obesity-related outcomes and adult attention-deficit/hyperactivity disorder. ADHD Atten Deficit and Hyperactivity Disord. 2015;7:S85-6.

51. Erhart M, Herpertz-Dahlmann B, Wille N, Sawitzky-Rose B, Holling H, Ravens-Sieberer U. Examining the relationship between attention-deficit/hyperactivity disorder and overweight in children and adolescents. Eur Child Adolesc Psychiatry. 2012;21:39-49.

52. Goulardins JB, Rigoli D, Piek JP, Kane R, Palacio SG, Casella EB, et al. The relationship between motor skills, ADHD symptoms, and childhood body weight. Res Dev Disabil. 2016;55:279-86.

53. Hanc T, Cieslik J, Wolanczyk T, Gajdzik M. Assessment of growth in pharmacological treatment-naive polish boys with attention-deficit/hyperactivity disorder. J Child Adolesc Psychopharmacol. 2012;22:300-6.

54. Ja JB. The relationship between attention deficit hyperactivity disorder and health-related physical fitness in university students. J Exerc Rehabil. 2014;10:367-71.

55. Kerekes N, Tajnia A, Lichtenstein P, Lundstrom S, Anckarsater H, Nilsson T, et al. Neurodevelopmental problems and extremes in BMI. PeerJ. 2015;2015 (7) (no pagination).

56. McClure HH, Eddy JM, Kjellstrand JM, Snodgrass JJ, Martinez Jr CR. Child and adolescent affective and behavioral distress and elevated adult body mass index. Child Psychiatry Hum Dev. 2012;43: 837-54.

57. Pagoto S, Curtin C, Appelhans BM, Alonso-Alonso M. Attention deficit/hyperactivity disorder and the clinical management of obesity. Curr Obes Rep. 2012;1:80-6.

58. van Egmond-Froehlich AWA, Weghuber D, de Zwaan M. Association of symptoms of attention-deficit/hyperactivity disorder with physical activity, media time, and food intake in children and adolescents. Plos One. 2012;7.

59. Anderson SE, Cohen P, Naumova EN, Must A. Relationship of childhood behavior disorders to weight gain from childhood into adulthood. Ambul Pediatr. 2006;6:297-301. 
60. Biederman J, Faraone SV, Monuteaux MC, Plunkett EA, Gifford J, Spencer T. Growth deficits and attention-deficit/hyperactivity disorder revisited: impact of gender, development, and treatment. Pediatrics. 2003;111:1010-6.

61. Curtin C, Bandini LG, Perrin EC, Tybor DJ, Must A. Prevalence of overweight in children and adolescents with attention deficit hyperactivity disorder and autism spectrum disorders: a chart review. BMC Pediatr. 2005;5:48.

62. Faraone SV, Biederman J, Monuteaux M, Spencer T. Long-term effects of extended-release mixed amphetamine salts treatment of attention-deficit/hyperactivity disorder on growth. J Child Adolesc Psychopharmacol. 2005; 15:191-202.

63. Holtkamp K, Konrad K, Muller B, Heussen N, Herpertz S, Herpertz-Dahlmann B, et al. Overweight and obesity in children with attention-deficit/hyperactivity disorder. Int J Obes Relat Metab Disord. 2004;28:685-9.

64. Hubel R, Jass J, Marcus A, Laessle RG. Overweight and basal metabolic rate in boys with attention-deficit/hyperactivity disorder. Eat Weight Disord. 2006;11:139-46.

65. Lam LT, Yang L. Overweight/obesity and attention deficit and hyperactivity disorder tendency among adolescents in China. Int J Obes (Lond). 2007;31:584-90.

66. Pagoto SL, Curtin C, Lemon SC, Bandini LG, Schneider KL, Bodenlos JS, et al. Association between adult attention deficit/ hyperactivity disorder and obesity in the US population. Obesity (Silver Spring). 2009;17:539-44.

67. Ptacek R, Kuzelova H, Paclt I, Zukov I, Fischer S. Anthropometric changes in non-medicated ADHD boys. Neuro Endocrinol Lett. 2009;30:377-81.

68. Spencer TJ, Biederman J, Harding M, O’Donnell D, Faraone SV, Wilens TE. Growth deficits in ADHD children revisited: evidence for disorder-associated growth delays? J Am Acad Child Adolesc Psychiatry. 1996;35:1460-9.

69. Spencer TJ, Faraone SV, Biederman J, Lerner M, Cooper KM, Zimmerman B, et al. Does prolonged therapy with a long-acting stimulant suppress growth in children with ADHD? J Am Acad Child Adolesc Psychiatry. 2006;45:527-37.
70. Swanson J, Greenhill L, Wigal T, Kollins S, Stehli A, Davies M, et al. Stimulant-related reductions of growth rates in the PATS. J Am Acad Child Adolesc Psychiatry. 2006;45:1304-13.

71.• Cortese S, Moreira-Maia CR, St Fleur D, Morcillo-Penalver C, Rohde LA, Faraone SV. Association between ADHD and obesity: a systematic review and meta-analysis. Am J Psychiatry. 2016;173: 34-43. The first meta-analysis on ADHD and obesity.

72. Agranat-Meged AN, Deitcher C, Goldzweig G, Leibenson L, Stein M, Galili-Weisstub E. Childhood obesity and attention deficit/ hyperactivity disorder: a newly described comorbidity in obese hospitalized children. Int J Eat Disord. 2005;37:357-9.

73. Altfas JR. Prevalence of attention deficit/hyperactivity disorder among adults in obesity treatment. BMC Psychiatry. 2002;2:9.

74. Braet C, Claus L, Verbeken S, Van Vlierberghe L. Impulsivity in overweight children. Eur Child Adolesc Psychiatry. 2007;16:47383.

75. Erermis S, Cetin N, Tamar M, Bukusoglu N, Akdeniz F, Goksen D. Is obesity a risk factor for psychopathology among adolescents? Pediatr Int. 2004;46:296-301.

76. Fleming JP, Levy LD, Levitan RD. Symptoms of attention deficit hyperactivity disorder in severely obese women. Eat Weight Disord. 2005;10:e10-13.

77. Davis C, Levitan RD, Smith M, Tweed S, Curtis C. Associations among overeating, overweight, and attention deficit/hyperactivity disorder: a structural equation modelling approach. Eat Behav. 2006;7:266-74.

78. Strimas R, Davis C, Patte K, Curtis C, Reid C, McCool C. Symptoms of attention-deficit/hyperactivity disorder, overeating, and body mass index in men. Eat Behav. 2008;9:516-8.

79. Cortese S, Isnard P, Frelut ML, Michel G, Quantin L, Guedeney A, et al. Association between symptoms of attention-deficit/hyperactivity disorder and bulimic behaviors in a clinical sample of severely obese adolescents. Int J Obes (Lond). 2007;31:340-6.

80. Levy LD, Fleming JP, Klar D. Treatment of refractory obesity in severely obese adults following management of newly diagnosed attention deficit hyperactivity disorder. Int J Obes (Lond). 2009;33: 326-34. 